Sains Peternakan Vol. 6 (2), September 2008: 22-30

ISSN 1693-8828

\title{
Analisis Investasi Usahatani Pembibitan Sapi Peranakan Limousine di Kabupaten Sleman
}

\author{
Shanti Emawati ${ }^{1)}$, Rini Widiati ${ }^{2)}$ dan I Gede Suparta Budisatria ${ }^{2)}$ \\ 1) Jurusan Peternakan Fakultas Pertanian, Universitas Sebelas Maret, Surakarta \\ ${ }^{2)}$ Program Studi Imu Peternakan, Fakultas Peternakan, Universitas Gadjah Mada, Yogyakarta \\ Email:emawati.shanti@gmail.com
}

\section{INTISARI}

Penelitian ini bertujuan untuk menentukan kelayakan finansial investasi usahatani pembibitan sapi Peranakan Limousine. Penelitian dilaksanakan mulai bulan Januari sampai dengan Mei 2007 dengan lokasi di Kabupaten Sleman. Metode penelitian yang digunakan adalah survei untuk mengumpulkan data primer dari responden dan data sekunder dari dinas terkait. Responden diambil secara purposive sampling. Analisis kelayakan finansial investasi usahatani pembibitan sapi potong menggunakan kriteria investasi benefit cost ratio (BCR), net present value (NPV), internal rate of return (IRR) dan payback period (PPC) berdasarkan umur investasi 7 tahun dengan discount factor 12\%/tahun. Hasil analisis menunjukkan bahwa usahatani pembibitan sapi Peranakan Limousine pada kondisi peternak di Kabupaten Sleman layak untuk diusahakan dengan nilai NPV $=\mathrm{Rp} 11.900 .156,00, \mathrm{IRR}=32,64 \%, \mathrm{BCR}=1,74$ dan payback period $=3,25$ tahun .

Kata kunci : Sapi Peranakan Limousine, Usaha pembibitan sapi, Analisis finansial investasi

\section{Investment Analysis of Limousine Cattle Breeding Farm in Sleman District}

\section{ABSTRACT}

The research was conducted to determine the feasibility of financial investment on Limousine cattle farming. Research was done from January to May 2007, located in Sleman District. Survey methods was done to collect primary data at the farm level and secondary data from related institution. Purposive sampling was applied to sellect farmers' respondent. Criteria used to analyze the feasibility of financial investment were consisted of Benefit Cost Ratio (BCR), Net Present Value (NPV), Internal Rate of Return (IRR) and Payback Period (PPC), based on 7 years investment and 12\% annual discount factor. The result showed that based on $N P V, I R R, B C R$ and payback period analysis, the most feasible investment of Limousine cattle breeding farm under farmers' condition with the value of $N P V=R p$ 11.900.156,00, IRR $=$ $32,64 \%, B C R=1,74$ and payback period $=3,25$ years.

Keywords : Limousine cattle, Cattle breeding farm, Investment financial analysis

PENDAHULUAN

Latar Belakang
Peranan ternak sapi sebagai pemasok daging cukup besar. Populasi sapi di Indonesia selama kurun waktu empat 
dasawarsa meningkat cukup signifikan ratarata 6,69 juta ekor selama kurun 1961 - 1970, menjadi 11 juta ekor pada tahun 1991 - 2006. Namun peningkatan populasi sapi belum dapat mencukupi permintaan daging sapi ditandai masih meningkatnya import khususnya setelah tahun 1991. Pada tahun 2005 pasokan daging sapi berasal dari impor mencapai $29,36 \%$ dari kebutuhan daging sapi dalam negeri.

Komoditas sapi potong memiliki prospek cerah bagi peternakan Indonesia, terlihat konsumsi daging sapi dalam lima tahun terakhir cenderung mengalami peningkatan rata-rata per tahun sebesar $11,07 \%$. Tahun 2001, konsumsi daging sapi sebesar 355.041,5 ton, kemudian tahun 2006 mengalami kenaikan menjadi sebesar $380.086,5$ ton. Meningkatnya permintaan masyarakat akan daging sapi yang belum diimbangi dengan peningkatan populasi akan menyebabkan pengurasan sapi potong terutama sapi bakalan dan pemotongan sapi betina produktif. Secara keseluruhan populasi sapi potong di Indonesia pada lima tahun terakhir, menurun rata-rata $0,49 \%$ per tahun. Pada tahun 2001, populasi sapi potong sebesar 11.137.701 ekor, kemudian tahun 2006 mengalami penurunan menjadi sebesar 10.835.686 ekor (Ditjen Peternakan, 2006).

Permasalahan yang dihadapi dalam usaha sapi potong di Indonesia adalah lebih dari $90 \%$ dipelihara oleh petani dengan cara tradisional, skala usaha kecil, usaha sambilan dan teknologi masih sederhana sehingga produktivitasnya rendah. Kasus pemotongan betina produktif yang mencapai $70 \%$ dari jumlah ternak betina yang dipotong menimbulkan pula dampak penurunan populasi sapi potong. Oleh karena itu perlu adanya pengembangan sapi potong pembibitan sebagai pensuplai sapi bakalan dan mengejar Program Kecukupan Daging tahun 2010 yang telah dicanangkan oleh Direktorat Jenderal Peternakan.

Kemampuan peternak kita dalam memproduksi ternak khususnya untuk bibit masih sangat terbatas karena pada usaha pembibitan sapi potong membutuhkan investasi yang cukup besar bila diukur oleh kemampuan peternak kecil dalam menyediakan modal. Demikian juga jangka waktu menghasilkan cukup lama, membutuhkan luangan waktu untuk memelihara yang relatif panjang. Meskipun demikian secara ekonomi modal atau investasi tidak menjadi masalah apabila suatu usaha profitable atau layak untuk diusahakan. Oleh karena itu, peneliti tertarik untuk mengadakan penelitian tentang analisis investasi untuk usahatani pembibitan sapi Peranakan Limousine.

\section{MATERI DAN METODE}

\section{Materi}

Penelitian dilaksanakan pada bulan Januari - Mei 2007 dengan lokasi di Kabupaten Sleman. Materi yang digunakan dalam penelitian adalah peternak pembibitan sapi Peranakan Limousine di Kabupaten Sleman, ternak sapi dan kuesioner.

\section{Metode}

\section{Metode penentuan lokasi}

Metode penentuan lokasi penelitian ditentukan secara sengaja, dengan lokasi contoh penelitian di Kabupaten Sleman dengan pertimbangan bahwa di lokasi tersebut terdapat beberapa kelompok tani ternak. Kelompok tani ternak yang diambil sebagai sampel penelitian ini adalah sebagai berikut : 
Tabel 1. Nama dan alamat kelompok tani ternak

\begin{tabular}{clllc}
\hline \hline No & Nama Kelompok Tani Ternak & \multicolumn{1}{c}{ Desa } & Kecamatan & Jumlah \\
\hline 1 & Sedyo Raharjo, Andini Harjo & Caturharjo & Sleman & 16 orang \\
\hline 2 & $\begin{array}{l}\text { Andini Gotro, Sido Maju, } \\
\text { Andini Jaya }\end{array}$ & Tambakrejo & Tempel & 20 orang \\
\hline 3 & Sido Rukun, Tlogowono & Jogotirto & Berbah & 12 orang \\
\hline 4 & Marangan, Gangsiran & $\begin{array}{l}\text { Bokoharjo, } \\
\text { Madurejo }\end{array}$ & Prambanan & 12 orang \\
\hline
\end{tabular}

Sumber : Data primer terolah, 2007

\section{Metode pengambilan sampel peternak}

Metode pengambilan sampel peternak dengan purposive sampling yaitu dipilih peternak dikelompok sampel yang telah memelihara induk sapi potong minimal 1 tahun dan pernah beranak. Jumlah sampel yang diambil dalam penelitian adalah 60 responden dengan pengambilan secara proporsional pada setiap kelompok. Pemilihan secara purposive berarti sampel dipilih dan ditetapkan berdasarkan pertimbanganpertimbangan tertentu yang sesuai dengan tujuan penelitian (Sugiyono, 2006).

\section{Metode pengambilan data}

Pengambilan data dilaksanakan dengan metode survey. Data yang diambil adalah data primer dan data sekunder. Data primer diperoleh dari wawancara kepada responden peternak sapi potong dengan menggunakan kuesioner. Data sekunder untuk menunjang data primer diperoleh dari Dinas Pertanian dan Kelautan, Sub Dinas Peternakan Sleman.

\section{Analisis Data}

\section{Koefisien teknis}

Koefisien teknis yang berpengaruh pada biaya dan penerimaan usaha pembibitan sapi potong Peranakan Limousine yaitu calving interval, service per conception, mortalitas dan umur penjualan pedet.

\section{Analisis biaya dan penerimaan}

Biaya yang diperlukan dalam analisis ini adalah biaya investasi dan biaya operasional. Penerimaan diperoleh dari penjualan pedet sebagai produk pokok dan penjualan kotoran sebagai produk sampingan.

\section{Analisis cash flow}

Analisis cash flow yang digunakan dalam analisis ini adalah memperhitungkan nilai output input sesuai dengan koefisien teknis dari pemeliharaan 2 ekor sapi induk Peranakan Limousine berdasarkan umur investasi 7 tahun dengan discount factor $12 \% /$ tahun.

\section{Analisis kriteria kelayakan}

Benefit cost ratio (BCR). Variabel yang diperlukan dalam analisis ini adalah gross benefit yang telah dipresent valuekan dengan total cost yang telah dipresent valuekan. Rumus yang digunakan adalah :

$$
\mathrm{BCR}=\frac{\text { Discounted gross benefit }}{\begin{array}{c}
\text { Discounted total } \\
\text { (Gittinger, 1986) }
\end{array}} \text { cost }
$$

Suatu usaha apabila nilai net $\mathrm{B} / \mathrm{C}$ ratio $>1$, maka proyek "go", sedangkan untuk nilai net $\mathrm{B} / \mathrm{C}$ ratio < 1 , maka proyek "no go" (Prawirokusumo, 1990).

Net present value (NPV). Variabel yang diperlukan dalam analisis ini adalah benefit 
dan cost yang telah dipresent valuekan dengan nilai tingkat discount rate. Rumus yang digunakan adalah :

$$
\mathrm{NPV}=\sum_{\mathrm{t}=1}^{\mathrm{n}} \frac{\mathrm{Bt}-\mathrm{Ct}}{(1+\mathrm{i})^{\mathrm{t}}}
$$

(Gittinger, 1986)

Keterangan : $\quad \mathrm{B}_{\mathrm{t}}=$ Benefit / keuntungan kotor yang diperoleh pada tahun $\mathrm{t}$

dikeluarkan pada tahun $\mathrm{t}$

$$
\mathrm{C}_{\mathrm{t}}=\text { Cost / biaya yang }
$$

(tahun)

$$
\begin{aligned}
& \mathrm{i}=\text { tingkat diskonto } \\
& \mathrm{n}=\text { umur ekonomi proyek }
\end{aligned}
$$

Suatu proyek apabila nilai NPV $>0$, maka proyek tersebut layak dijalankan. Jika NPV = 0 , berarti proyek tersebut mengembalikan persis sebesar social opportunity cost of capital. Jika NPV < 0, proyek supaya ditolak artinya adanya penggunaan lain yang lebih menguntungkan untuk sumber-sumber yang diperlukan proyek (Kadariah et al., 1999).

Internal rate of return (IRR). Variabel yang diperlukan dalam analisis adalah benefit dan cost yang telah dipresent valuekan. Rumus yang digunakan adalah :

$I R R=i^{\prime}+\left[\frac{N P V^{\prime}}{N P V^{\prime}+N P V^{\prime}}\right] X\left(i^{\prime \prime}-i^{\prime}\right)$

(Prawirokusumo, 1990)

$$
\begin{array}{r}
\text { Keterangan : NPV' }=\text { NPV yang positif } \\
\text { NPV” }=\text { NPV yang negatif } \\
\text { i' = tingkat bunga yang } \\
\text { menghasilkan NPV positif } \\
\text { i” = tingkat bunga yang } \\
\text { menghasilkan NPV negatif }
\end{array}
$$

Suatu usaha apabila nilai IRR $>$ social discount rate, maka usaha tersebut akan layak dan apabila nilai IRR < social discount rate, maka proyek tersebut tidak akan layak (Pudjosumartono, 1995).
Payback period. Variabel yang diperlukan dalam analisis payback period adalah perbandingan modal/investasi dengan rata-rata net benefit per tahun. Rumus yang digunakan adalah :

$$
\text { Payback period }=\frac{\mathrm{C}}{\mathrm{E}}
$$

$$
\text { Keterangan : } \begin{aligned}
\mathrm{C}=\text { modal } / \text { investasi } \\
\mathrm{E}=\text { rata-rata } \text { net benefit } \text { per } \\
\text { tahun }
\end{aligned}
$$

(Prawirokusumo, 1990)

\section{Batasan Operasional}

Peternak yang diambil sebagai sampel dalam penelitian adalah peternak yang mengusahakan pembibitan sapi potong dengan memiliki induk yang telah beranak minimal 1 ekor dan telah dipelihara minimal 1 tahun. Perhitungan berdasarkan umur investasi 7 tahun dengan discount factor $12 \% /$ tahun sesuai dengan tingkat bunga yang berlaku pada usahatani ternak tersebut. Perhitungan produksi meliputi produk pokok berupa penjualan pedet dan produk sampingan berupa penjualan kotoran. Opportunity cost tenaga kerja yang tidak dibeli.

\section{HASIL DAN PEMBAHASAN}

\section{Identitas Peternak}

\section{Umur peternak}

Umur peternak sapi potong di lokasi penelitian berkisar antara $25-80$ tahun dengan rata-rata 50 tahun. Umur peternak digolongkan menjadi 3 kelompok yaitu petani taruna yang berusia antara $15-25$ tahun, petani muda yang berusia antara $25-44$ tahun dan petani dewasa yang berusia diatas 45 tahun (Soegiharto, 2004). Berdasarkan penelitian bahwa $66,33 \%$ peternak berusia di atas 45 tahun. Menurut Soegiharto (2004) 
bahwa sektor pertanian menunjukkan tren aging agriculture, yaitu suatu kondisi dimana tenaga kerja yang berada di pertanian adalah tenaga kerja berusia lanjut.

\section{Tingkat pendidikan peternak}

Hasil penelitian menunjukkan bahwa peternak sebagian besar berpendidikan cukup tinggi karena 55\% sudah mengenyam pendidikan 9 tahun. Tingkat pendidikan peternak tersebut berpengaruh terhadap manajemen peternakan yang dilakukan. Pendidikan peternak menggambarkan kemampuan mengelola ternak sapi. Menurut Mosher (1987), tingkat pendidikan memiliki peran penting dalam memahami penggunaan teknologi untuk dapat meningkatkan produktivitas usaha pertanian karena dengan semakin tinggi tingkat pendidikan maka akan lebih mudah memahami dan menerapkan teknologi baru.

\section{Pekerjaan peternak}

Pekerjaan utama masyarakat sebagian besar adalah petani sebesar $68,33 \%$. Peternak mengusahakan pembibitan sapi potong hanya sebagai pekerjaan sampingan yang berguna untuk membantu menambah penghasilan keluarga sehingga dapat meningkatkan taraf hidup peternak.

\section{Aspek Teknis Pembibitan Sapi Peranakan Limousine}

\section{Sapi bibit}

Induk sapi yang diambil sebagai sampel dalam penelitian ini adalah bangsa sapi
Peranakan Limousine. Alasan peternak memilih bangsa sapi tertentu antara lain : mudah memelihara karena pakan yang dibutuhkan relatif sedikit sehingga mereka mampu menyediakannya setiap hari; alasan lainnya adalah untuk penyediaan pakan tidak menjadi masalah karena memiliki cadangan pakan yang cukup baik hijauan maupun jerami dan konsentrat sehingga memilih bangsa sapi yang pertumbuhannya relatif cepat walaupun membutuhkan pakan yang relatif lebih banyak. Sapi induk yang dimiliki oleh responden telah beranak berkisar $2-7$ kali.

\section{Pakan, kandang dan sewa lahan}

Pada umumnya sapi-sapi dipelihara secara intensif yaitu dikandangkan sepanjang hari dengan disediakan pakan yang cukup. Pakan yang diberikan berupa hijauan dan konsentrat. Sebagian besar peternak memelihara ternaknya dengan sistem kandang kelompok yang dibangun dalam suatu lokasi dengan luas kaplingan yang sama. Bagi peternak yang memiliki skala kepemilikan diatas rata-rata maka mereka akan memerlukan lebih dari satu lokal kaplingan. Iuran dan sewa lahan yang ditetapkan masingmasing kelompok berbeda-beda mulai dari Rp $1.000,00$ hingga Rp 100.000,00 pertahun.

\section{Koefisien teknis}

Koefisien teknis calving interval dan umur penjualan pedet akan berpengaruh pada penerimaan dan biaya produksi. Berdasarkan data primer hasil survei, koefisien teknis disajikan seperti Tabel 2.

Tabel 2.Koefisien teknis usaha pembibitan sapi Peranakan Limousine di Kabupaten Sleman

\begin{tabular}{lc}
\hline \multicolumn{1}{c}{ Koefisien teknis } & Sapi Peranakan Limousine \\
\hline Calving interval & $16,24 \pm 1,44 \mathrm{bln}$ \\
Penjualan pedet & $7,91 \pm 5,36 \mathrm{bln}$ \\
\hline
\end{tabular}

Sumber : Data primer terolah, 2007 


\section{Aspek Finansial Usahatani Pembibitan Sapi Peranakan Limousine}

\section{Investasi usahatani pembibitan sapi Peranakan Limousine}

Untuk mengetahui lebih jelas besarnya masing-masing komponen investasi pada sapi Peranakan Limousine maka disajikan Tabel 3.

Tabel 3. Investasi usahatani pembibitan 2 ekor induk sapi/tahun di Kab. Sleman

\begin{tabular}{|c|c|}
\hline Komponen investasi & Nilai investasi sapi Peranakan Limousine (Rp) \\
\hline Kandang & 1.220 .588 \\
\hline Sapi bibit & 11.860 .235 \\
\hline Peralatan & 300.354 \\
\hline Total & 13.381 .177 \\
\hline
\end{tabular}

Sumber : Data primer terolah, 2007

Pada Tabel 3 terlihat bahwa biaya investasi sapi Peranakan Limousine cukup besar. Besarnya nilai investasi tersebut disebabkan oleh tingginya biaya yang dikeluarkan peternak untuk bibit dan pembuatan kandang. Variasi material yang digunakan dalam pembuatan kandang antara peternak satu dengan peternak lain berbedabeda, tergantung kemampuan modal yang dimiliki peternak.

\section{Biaya operasional usahatani pembibitan sapi Peranakan Limousine}

Biaya operasional pada usahatani pembibitan sapi Peranakan Limousine ini diperhitungkan secara tunai dan nontunai yang dinilai berdasarkan opportunity costnya. Biaya operasional sapi Peranakan Limousine dapat dilihat pada Tabel 4.

Tabel 4. Biaya operasional usahatani pembibitan 2 ekor induk/thn di Kab. Sleman

\begin{tabular}{lc}
\hline \hline Komponen biaya operasional & Biaya operasional sapi Peranakan Limousine $(\mathrm{Rp})$ \\
\hline Iuran & 3.000 \\
Sewa lahan pakan & 11.324 \\
Sewa lahan kandang & 28.824 \\
Konsentrat & 2.293 .059 \\
IB & 38.067 \\
Kesehatan & 6.118 \\
Obat-obatan & 16.735 \\
Tenaga kerja & 298.575 \\
Peralatan & 14.412 \\
\hline \multicolumn{2}{c}{ Total } \\
\hline
\end{tabular}

Sumber : Data primer terolah, 2007

Biaya operasional pada usahatani pembibitan sapi Peranakan Limousine terbesar adalah terletak pada biaya pakan terutama konsentrat. Sesuai dengan pendapat Prawirokusumo (1990) bahwa biaya pakan biasanya terbesar dalam usaha peternakan yaitu berkisar antara $60-80 \%$ dari total biaya.

\section{Penerimaan usahatani pembibitan sapi Peranakan Limousine}

Pada usahatani pembibitan sapi Peranakan Limousine ini, penerimaan peternak berasal dari penjualan pedet sebagai produk pokok dan pupuk kandang sebagai 
produk sampingan yang dihasilkan oleh peternak serta nilai induk afkir.

\section{Analisis Finansial}

\section{Analisis investasi usahatani}

Analisis investasi usahatani pada penelitian ini menggunakan umur investasi 7 tahun, yaitu berdasarkan umur produktif induk 7 tahun atau induk umur sekitar 9 tahun dan merupakan hasil penghitungan untuk pemeliharaan 2 ekor induk sapi.

Pada penelitian ini, peternak memelihara induk antara 1,5 sampai 9 tahun. Lama waktu memelihara induk tergantung kepada kondisi ternak dan kepentingan sosial peternak. Hal ini berarti apabila peternak membutuhkan uang tunai, peternak yang tidak memiliki pedet atau ternak jantan lainnya akan menjual induk miliknya, namun ada juga peternak yang tetap mempertahankan induk miliknya karena memiliki produktivitas yang dirasa cukup baik. Biasanya ternak dijual untuk keperluan biaya sekolah, biaya pengobatan dan biaya untuk acara keluarga.

Diasumsikan umur produktif induk 7 tahun adalah berdasarkan pengalaman peternak untuk induk-induk berkualitas baik dapat mereka pelihara hingga lebih kurang 9 tahun. Berdasarkan kemampuan biologis ternak sapi bahwa seekor sapi betina rata-rata memiliki umur afkir kurang lebih 10 tahun (Soekardono, 2006).

\section{Analisis cash flow}

Analisis cash flow memperhitungkan nilai aliran penerimaan uang tunai dan nontunai yang dinilai uangkan dengan opportunity cost (input cash flow) serta aliran biaya yang semua dinilai uangkan (outflow cash flow). Berdasarkan hasil penelitian, nilai cumulatif net cash flow untuk sapi Peranakan Limousine cukup tinggi. Hal ini disebabkan tingginya nilai penjualan pedet sapi Peranakan Limousine sehingga menghasilkan keuntungan.

Semakin besar nilai cumulatif net cash flow yang diperoleh menunjukkan bahwa usahatani pembibitan sapi Peranakan Limousine yang dijalankan peternak mendapatkan keuntungan. Tetapi perhitungan tersebut belum dapat digunakan sebagai indikator kelayakan usaha karena belum di discount factor. Hasil tersebut hanya menunjukkan bahwa pada periode pemeliharaan tertentu telah dicapai hasil yang positif. Oleh karena itu perlu dilakukan analisis investasi yang memperhitungkan nilai uang di masa mendatang dengan menggunakan discount factor. Perhitungan cash flow dibuat dalam jangka waktu 7 tahun berdasarkan umur ekonomis induk sapi potong.

\section{Analisis kelayakan finansial}

Analisis kelayakan finansial sangat penting dilakukan karena untuk mengetahui apakah usaha yang dijalankan tersebut dalam jangka waktu tertentu dapat mendatangkan keuntungan atau tidak bagi peternak. Untuk mengetahui kelayakan usaha yang dijalankan, maka digunakan tiga kriteria uji kelayakan yaitu NPV, IRR dan BCR dengan menggunakan discount rate $12 \%$ dan jangka waktu investasi 7 tahun. Besarnya nilai kriteria finansial tersaji pada Tabel 5 .

Tabel 5. Kriteria finansial usahatani pembibitan sapi Peranakan Limousine di Kab. Sleman

\begin{tabular}{lc}
\hline \multicolumn{1}{c}{ Kriteria finansial } & Nilai kriteria finansial sapi Peranakan Limousine \\
\hline NPV & Rp $11.900 .156,00$ \\
BCR & 1,74 \\
IRR & $32,64 \%$ \\
Payback period & 3,25 tahun \\
\hline
\end{tabular}

Sumber : Data primer terolah, 2007 
Berdasarkan Tabel 5 terlihat bahwa usahatani pembibitan sapi Peranakan Limousine layak untuk dijalankan karena NPV bernilai positif, BCR $>1$ dan IRR $>$ discount factor.

Kriteria NPV. Analisis NPV penting dilakukan karena sejumlah uang tertentu pada saat sekarang mempunyai nilai berbeda dimasa mendatang. NPV merupakan seluruh angka net cash flow yang digandakan dengan discount factor pada tahun dan tingkat bunga yang telah ditentukan (Prawirokusumo, 1990). Suatu usahatani pembibitan sapi potong dikatakan layak untuk dijalankan apabila NPV bernilai positif. Penelitian ini menggunakan discount factor $12 \%$ berdasarkan tingkat bunga bank yang berlaku saat penelitian. Nilai NPV sapi Peranakan Limousine adalah sebesar Rp 11.900.156,00 /7 tahun. Hal ini berarti keuntungan yang diperoleh peternak cukup besar yaitu sebesar Rp 1.700.022,00/tahun untuk pemeliharaan 2 ekor induk.

Kriteria BCR. BCR merupakan perbandingan antara hasil antara hasil yang dipresent-valuekan dengan biaya modal sebagai indikator bisa diterima atau tidaknya suatu investasi yang dijalankan. Suatu usahatani pembibitan sapi potong layak dijalankan apabila nilai BCR $>1$ (Kadariah et al., 1999).

Berdasarkan hasil penelitian, nilai BCR pada sapi Peranakan Limousine bernilai lebih dari satu yaitu sebesar 1,74. Hal ini berarti usahatani pembibitan sapi Peranakan Limousine layak dijalankan karena penerimaan yang diperoleh peternak lebih besar daripada biaya yang dikeluarkan.

Kriteria IRR. IRR merupakan tingkat keuntungan bersih atas investasi karena benefit bersih yang positif ditanam kembali dalam tahun berikutnya dan mendapatkan tingkat bunga yang sama selama sisa umur proyek (Prawirokusumo, 1990). Suatu usahatani pembibitan sapi potong layak dijalankan apabila nilai IRR lebih besar dari
$12 \%$ yaitu tingkat bunga (discount rate) yang berlaku saat penelitian.

Hasil penelitian menunjukkan bahwa pada sapi Peranakan Limousine memiliki nilai IRR lebih besar dari $12 \%$ yaitu sebesar $32,64 \%$. Hal ini berarti peternak mampu mengembalikan investasi yang ditanamkan.

Payback period. Payback period menunjukkan jangka waktu yang diperlukan untuk mengembalikan seluruh modal yang digunakan pada investasi awal. Apabila payback period tersebut lebih pendek dari umur investasi, maka usaha tersebut menguntungkan sehingga layak untuk dijalankan, namun apabila payback period tersebut lebih panjang dari umur investasi maka usaha tersebut tidak layak dijalankan (Husnan dan Suwarsono, 2005).

Berdasarkan penelitian diperoleh bahwa nilai payback period sapi Peranakan Limousine sebesar 3,25 tahun. Hal ini berarti dalam kurun waktu kurang dari empat tahun dapat mengembalikan investasi sehingga usahatani pembibitan sapi Peranakan Limousine layak untuk dijalankan karena dapat cepat mengembalikan investasi. Menurut Cholig (1999), semakin cepat waktu pengembalian maka semakin baik untuk diusahakan.

\section{KESIMPULAN}

Berdasarkan analisis kelayakan finansial investasi, usahatani pembibitan sapi Peranakan Limousine pada kondisi peternak di Kabupaten Sleman dengan menggunakan umur investasi 7 tahun, discount factor 12\%, dengan pemeliharaan 2 ekor induk layak untuk terus dijalankan dengan nilai $\mathrm{NPV}=\mathrm{Rp}$ 11.900.156,00, IRR $=32,64 \%, \mathrm{BCR}=1,74$ dan payback period $=3,25$ tahun.

\section{DAFTAR PUSTAKA}

Choliq, A., H.R.A.Wirasasmita dan S. Hasan. 1999. Evaluasi Proyek, Suatu Pengantar. Pioner Jaya. Bandung. 
Ditjen Peternakan. 2006. Statistik Peternakan.

Direktorat Jenderal Peternakan. Departemen Pertanian RI. Jakarta.

Gittinger, J.P. 1986. Analisa Ekonomi Proyek-Proyek Pertanian. UI-Press. Jakarta.

Husnan, S. dan Suwarsono. 2005. Studi Kelayakan Proyek. Fakultas Ekonomi. Universitas Gadjah Mada. Yogyakarta.

Kadariah, L. Karlina dan C. Gray. 1999. Pengantar Evaluasi Proyek. Fakultas Ekonomi. Universitas Indonesia, Jakarta.

Mosher, A.T. 1987. Menggerakkan dan Membangun Pertanian, Syarat-Syarat Pokok Pembangunan dan Modernisasi. CV Yasaguna. Jakarta.
Prawirokusumo, S. 1990. Ilmu Usaha Tani. Edisi I. BPFE. Yogyakarta.

Pudjosumartono, M. 1995. Evaluasi Proyek, Uraian Singkat dan Soal Jawab. Liberty. Yogyakarta.

Soegiharto, S. 2004. Potret Tenaga Kerja di Sektor Pertanian. Kapus Litbang Ketransmigrasian-Balitfo. Jakarta.

Soekardono, 2006. Ekonomi Agribisnis Peternakan, Teori, Bahasan dan Aplikasinya. Laboratorium Sosek. Fakultas Peternakan. Universitas Mataram.

Sugiyono. 2006. Metode Penelitian Bisnis. Cetakan 9. CV Alfabeta. Bandung. Susieni, A. 2003. Studi Kelayakan Bisnis. Cetakan 2. Penerbit Andi. Yogyakarta. 